\title{
CLINICO-MICROBIOLOGICAL ASPECT OF CHRONIC SUPPURATIVE OTITIS MEDIA
}

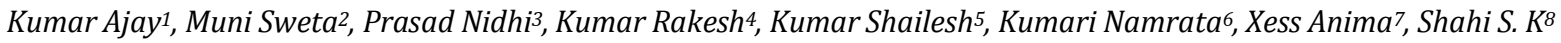

${ }^{1}$ Senior Resident, Department of Microbiology, Indira Gandhi Institute of Medical Sciences (IGIMS), Patna.

2Senior Resident, Department of Microbiology, Indira Gandhi Institute of Medical Sciences (IGIMS), Patna.

${ }^{3}$ Assistant Professor, Department of Microbiology, Indira Gandhi Institute of Medical Sciences (IGIMS), Patna.

${ }^{4}$ Assistant Professor, Department of Microbiology, Indira Gandhi Institute of Medical Sciences (IGIMS), Patna.

${ }_{5}^{5}$ Additional Professor, Department of Microbiology, Indira Gandhi Institute of Medical Sciences (IGIMS), Patna.

${ }^{6}$ Additional Professor, Department of Microbiology, Indira Gandhi Institute of Medical Sciences (IGIMS), Patna.

7 Professor, Department of Microbiology, Indira Gandhi Institute of Medical Sciences (IGIMS), Patna.

${ }^{8}$ Professor, Department of Microbiology, Indira Gandhi Institute of Medical Sciences (IGIMS), Patna.

\section{ABSTRACT}

\section{BACKGROUND}

Chronic suppurative otitis media (CSOM) is a disease of multiple aetiology and its importance lies in its chronicity and dreaded complications. Both Gram-positive and negative organisms are responsible for infection of the middle ear. Due to advent of newer and sophisticated antibiotics, the microbiological flora is changing constantly. This requires a reappraisal of the flora in CSOM and their in vitro antibiotic sensitivity pattern in cases of CSOM, which do not respond to local antibiotics. The frequent presence of CSOM in general practice and its poor response to the routine treatment are the factors responsible for undertaking this study.

\section{MATERIALS AND METHODS}

One hundred and fifty patients with tubotympanic type of CSOM were prospectively studied. They had chronic ear discharge and had not received antibiotics for the previous five days. Swabs were taken and cultured for bacteria. The standard method of isolation and identification was followed. Antimicrobial susceptibility of the bacterial isolates was performed by Kirby-Bauer's disc diffusion method.

\section{RESULTS}

Analysis of bacterial flora of the present study showed predominance of Gram-negative bacilli (41.4\%). The highest incidence (36.5\%) was that of Pseudomonas aeruginosa followed by Staphylococcus aureus (29.5\%). Overall most sensitive antibiotic groups were Fluoroquinolones and Cephalosporins and least effective were Penicillin and Macrolides.

\section{CONCLUSION}

The outcome of our study enabled us to set an empirical medical treatment for an early resolution of ear discharge and inflammation in our patients with CSOM as we could understand the aetiological pathogens and their susceptibility pattern. Effective medical treatment in obtaining a discharge free ear prior to surgical treatment led us to improve the surgical outc ome in our patients with CSOM.

\section{KEYWORDS}

Chronic Suppurative Otitis Media, Aerobic bacterial isolates, Antibiotic Resistance.

HOW TO CITE THIS ARTICLE: Ajay K, Sweta M, Nidhi P, et al. Clinico-microbiological aspect of chronic suppurative otitis media. J. Evolution Med. Dent. Sci. 2017;6(7):562-564, DOI: 10.14260/Jemds/2017/120

\section{BACKGROUND \\ Chronic suppurative otitis media (CSOM) is a disease of} multiple aetiology and is well known for its persistence and recurrence, despite treatment. CSOM is a destructive disease with irreversible sequelae and can proceed to serious intra and or extracranial complications.[1] The microbiological flora of the middle ear varies and depends on the type of otitis media. In the acute form, the major organisms present are Haemophilus influenzae, Streptococcus pneumoniae, Pseudomonas aeruginosa and anaerobic bacteria.[2] CSOM has

Financial or Other, Competing Interest: None.

Submission 15-12-2016, Peer Review 08-01-2017,

Acceptance 16-01-2017, Published 23-01-2017.

Corresponding Author:

Dr. Kumar Ajay,

Senior Resident,

Department of Microbiology,

Indira Gandhi Institute of Medical

Sciences (IGIMS), Patna-14.

E-mail:dr.ajay876@gmail.com

DOI: $10.14260 /$ jemds $/ 2017 / 120$ received considerable attention, not only because of its high incidence and chronicity, but also because of issues such as bacterial resistance and ototoxicity with both topical and systemic antibiotics.[2] The wide spread use of antibiotics has precipitated the emergence of multiple resistant strains of bacteria which can produce both primary and post-operative ear infections. The indiscriminate, haphazard and hay-hearted use of antibiotics and the poor followup of the patients have resulted in the persistence of low-grade infections. The changes in the microbiological flora following the advent of sophisticated synthetic antibiotics have increased the relevance of the reappraisal of the modern day flora in CSOM, and their in vitro antibiotic sensitivity pattern is very important for the clinician to plan a general outline of treatment for a patient and can minimise complications that may require surgery for a chronically discharging ear.[3] The study of bacteriology and drug sensitivity is necessary to enable the treating family physician to plan the general management of CSOM and it is almost essential for the ENT surgeon to make the discharging ear dry for better results of myringoplasty and ossiculoplasty. ${ }^{[4]}$ The objective of this study 
is to determine the aetiological agents and their antibiotic susceptibility pattern in CSOM patients for appropriate treatment.

\section{MATERIALS AND METHODS}

One hundred and fifty patients, who presented to the ENT Department from March 2013 to August 2014 with a history of chronic discharging ear were prospectively studied. Two sterile cotton swabs were used to collect ear discharge from CSOM patients. Only those cases were selected who had not taken any treatment either systemic or local in the form of ear drops for the last seven days. One swab was used for performing Gram stain and $\mathrm{KOH}$ preparation and second one for culture. Culture was done on nutrient agar, blood agar, Mac-Conkey agar and SDA. The organisms were identified by culture characters, morphology, and pigment production, beta-haemolysis on blood agar, motility and conventional biochemical tests. Antimicrobial susceptibility test for all isolates was performed on Mueller-Hinton agar plate using Kirby-Bauer disc diffusion method. Antibiotic discs were procured from HiMedia Labs Mumbai. Results were interpreted using Clinical Laboratory Standards Institute (CLSI) guidelines. ${ }^{[5]}$

\section{RESULTS}

Out of 152 swabs, 30 (19.7\%) were sterile while 122 (80.2\%) yielded growth of organisms. Isolation of bacteria was done in 119 (78.2\%) ears while 3 ears revealed fungal growth as Candida albicans in two and Aspergillus flavus in one of the cases. The most common organisms isolated were Pseudomonas aeruginosa 42 (36.5\%) and Staphylococcus aureus 34 (29.5\%) followed by other Enterobacteriaceae members like Proteus spp., Escherichia coli, Klebsiella and Citrobacter. Details of various isolates from CSOM samples are depicted in Table 1 . No growth was observed in 30 (19.7\%) samples.

Most sensitive antibiotic groups were Fluoroquinolones and Cephalosporins and least effective were Penicillins and Macrolides. Cephalosporins and fluoroquinolones showed maximum sensitivity with $97 \%$ \& $100 \%$ and $76 \%, 83 \%$ sensitivity for Pseudomonas spp. and Staphylococcus aureus respectively.

\begin{tabular}{|c|c|c|c|}
\hline Gram Stain & Isolate & No. & \% \\
\hline \multirow{4}{*}{$\begin{array}{c}\text { Gram } \\
\text { Negative } \\
\text { (n=67) }\end{array}$} & Pseudomonas spp. & 42 & $36.5 \%$ \\
\cline { 2 - 4 } & Proteus spp. & 13 & $11.3 \%$ \\
\cline { 2 - 4 } & E.coli & 4 & $3.4 \%$ \\
\cline { 2 - 4 } & Klebsiella spp. & 4 & $3.4 \%$ \\
\hline \multirow{2}{*}{$\begin{array}{c}\text { Gram } \\
\text { Positive } \\
\text { (n=52) }\end{array}$} & $\begin{array}{c}\text { Staphylococcus } \\
\text { Aureus }\end{array}$ & 34 & $29.5 \%$ \\
\cline { 2 - 4 } & $\begin{array}{c}\text { Coagulase Negative } \\
\text { Staph }\end{array}$ & 18 & $15.6 \%$ \\
\cline { 2 - 4 } & \multicolumn{3}{|c}{} \\
\hline \multicolumn{3}{|c|}{ Table 1. Bacterial Isolation from CSOM samples (n-119) } \\
\hline
\end{tabular}

\section{DISCUSSION}

CSOM is a condition of the middle ear that is characterised by persistent or recurrent discharge through a chronic perforation of the tympanic membrane. Untreated cases of CSOM can result in a broad range of complications. Thirty (19.7\%) samples were sterile in the present study. This is in comparison with the results found by Kumar et al[6] (4.39\%) and Vijaya et al[7] $(5.28 \%)$, while Chakraborty et al[8]
(12.6\%), Vijaya et al[7] (17.6\%), and Fatma et al[9] (16.9\%) found higher percentage of sterile samples. This may be due to prior antibiotic therapy. All samples in the present study yielded single type of organism. Kumar et al[6] and Fatma et al[9] also reported $93.1 \%$ and $94 \%$ of monobacterial growth in their studies, respectively, while Vijaya (1998)[10] reported only in $51 \%$ of samples.

Our results show that active CSOM infection is mainly due to Pseudomonas aeruginosa (36.5\%) and Staphylococcus aureus (29.5\%). The third most commonly isolated organism, coagulase-negative Staphylococcus, may represent skin flora contamination, and not be a true pathogen. This finding is in tandem with the pattern of CSOM infection within the tropical region. It is seen that both Gram-positive and Gram-negative organisms are responsible for infection of middle ear. It is usually seen that Gram-negative rods outnumber the Gram-positive organism in CSOM. In the present study, Pseudomonas aeruginosa was the predominant organism followed by Proteus spp. These findings are in accordance with those of many previous authors,[6,8,9,11,12] A H C Loy (2002),[13] Lakshmipathi and Bhaskaran (1965),[14] Gulati et al,[15] Ayyagari et al[16] while Vijaya et al[17] found Klebsiella as the predominant isolate in CSOM cases. The findings of predominant Gram-negative bacilli is consistent with many previous investigators,[6,8,11,12,18] Gulati et al,[15] Rajendra Kumar (1975),[19] Gulati et al,[20] Mishra et al[21] while studies conducted by various investigators [Table 3] ${ }^{[4,7,10,17,22]}$ Singh and Bhaskar (1972),[23] Rao et al,[24] Rao and Reddy (1994),[25] Friedmann (1957)[26] found Staphylococcus aureus to be the most common causative organism, [1] which is the second common isolate in our study. All the pathogenic strains isolated in the present series were tested against various antibiotics Kumar et al,[6] and Chakraborty et al[8] also reported $95.40 \%$ of resistance to amoxicillin among CSOM isolates. $40-50 \%$ of Pseudomonas aeruginosa isolates have shown resistance to piperacillin, ceftazidime, Ampicillin, but sensitivity was moderately good for Gentamicin, and ciprofloxacin. All other Isolates are sensitive to routinely used antibiotics. Amikacin was found to be the most effective drug followed by Gentamicin, Ciprofloxacin, and Cefoperazone. These findings are in accordance with those of Gulati et al,[20] and Mishra et al.[21] S. aureus was fairly sensitive to erythromycin, gentamicin and ciprofloxacin. This is in comparison with the reports of Hegde et al,[12] and Goyal et al.[11] In the present study, gentamicin with fair susceptibility pattern is more effective in treating. $90 \%$ of isolates showed resistance to amoxicillin.

\begin{tabular}{|c|c|c|c|c|c|c|}
\hline Organism & Amp & $\begin{array}{c}\text { Amox- } \\
\text { Clav }\end{array}$ & Macro & Amino & Cepha & Fluro \\
\hline $\begin{array}{c}\text { Pseudomonas } \\
\text { spp. }\end{array}$ & $23 \%$ & $15 \%$ & $22 \%$ & $60 \%$ & $97 \%$ & $100 \%$ \\
\hline $\begin{array}{c}\text { Staphylococcus } \\
\text { Aureus }\end{array}$ & $36 \%$ & $55 \%$ & $18 \%$ & $55 \%$ & $76 \%$ & $83 \%$ \\
\hline $\begin{array}{c}\text { Coagulase } \\
\text {-ve Staph }\end{array}$ & $92 \%$ & $100 \%$ & $12 \%$ & $100 \%$ & $100 \%$ & $100 \%$ \\
\hline Proteus spp. & $17 \%$ & $19 \%$ & $34 \%$ & $67 \%$ & $86 \%$ & $90 \%$ \\
\hline \multicolumn{7}{|c|}{ Table 2. Sensitivity Pattern for Common } \\
Bacterial Isolates (n=107) \\
\hline
\end{tabular}

Amp=Ampicillin; Amox-clav=Amoxicillin-Clavulanic Acid; Macro=Macrolides; Amino=Aminoglycosides; Cepha= Cephalosporins; Floro=Fluoroquinolones. 
CSOM as majority of pathogens in CSOM cases are susceptible to it. When used topically, gentamicin induced ototoxicity is rare.[12] When the results of various workers were compared, one fact became obvious that the bacteriology and antibiotic sensitivity pattern of CSOM has been changing from time to time. The strains of yesterday which were sensitive to Streptomycin, Tetracycline and Chloramphenicol no longer exhibit the old sensitivity pattern today. These drugs have been replaced by aminoglycosides, quinolones and cephalosporins.[1]

Pseudomonas continues to remain supreme as a primary offender and poses problem for effective therapeutic control.[11] Staphylococcus aureus bear the inherent trait of resistance. In the era of antibiotics, the emergence of antibiotic resistance is becoming more common. Patient noncompliance is an important factor responsible for the development of antibiotic resistance. As soon as symptoms subside, many patients stop taking antibiotics before completion of therapy and allow partially resistant microbes to flourish. Such practice should be condemned strongly and patients should be educated to avoid the same.

For the antibiotics commonly available locally as topical eardrops, gentamicin and ciprofloxacin were shown to be the most effective, with good sensitivities for the commonly isolated organisms. With specific regard to the two most common pathogens in CSOM, Pseudomonas aeruginosa was found to be more resistant to commonly used antibiotics, while Staphylococcus aureus showed moderately good sensitivity to all antibiotics tested. Gentamicin eardrops thus appear to be an effective first-line topical antibiotic in the treatment of active CSOM.[13]

\section{CONCLUSION}

Knowledge of the pathogens and antibiotic sensitivity pattern responsible for CSOM and choosing suitable antibiotics according to susceptibility tests should guide the management of disease treatment and reduces intracranial and extracranial complications with CSOM.

\section{REFERENCES}

[1] Poorey VK, Lyer A. Study of bacterial flora in CSOM and its clinical significance. Indian J Otolaryngol Head Neck Surg 2002;54(2):91-5.

[2] Nikakhlagh S, Khosravi AD, Fazlipour A, et al. Rashidi microbiologic findings in patients with chronic suppurative otitis media. J Med Sci 2008;8(5):503-6.

[3] Kumar H, Seth S. Bacterial and fungal study of 100 cases of chronic suppurative otitis media. J Clin Diagn Res 2011;5:1224-7.

[4] Taneja MK. CSOM: a bacteriological study. Indian J Otol 1995;1(2):24-7.

[5] National Committee for Clinical Laboratory Standards. Performance standards for antimicrobial susceptibility testing. USA, Wayne, PA: NCCLS 2001:M100-S1.

[6] Kumar S, Sharma S, Saxena, et al. A study of bacterial flora and sensitivity to antibiotics in cases of CSOM TTD in western UP. Indian J Otol 2008;14:20-4.

[7] Vijaya D, Nagarathnamma T. Microbiological study of chronic suppurative otitis media. Indian J Otol 1998;4:172-4.
[8] Chakraborty A, Bhattacharjee A, Purkaystha P. Microbiological profile of chronic suppurative otitis media: its significance in north-east India. Indian J Otol 2005;11:39-44.

[9] Fatma AA, Assiry S, Siraj MZ. Microbiological evaluation and aspects on management of chronic suppurative otitis media in Riyadh. Indian J Otol 1998;4:115-20.

[10] Vijaya D. Aerobes, anaerobes, and fungi in chronic suppurative otitis media. Indian J Otol 2000;6:55-8.

[11] Goyal R, Aher A, De S, et al. Chronic suppurative otitis media-a clinico microbiological study. Indian J Otol 2009;15:18-22.

[12] Hedge MC, Bhat GK, Sreedharan S, et al. Bacteriological study of tubotympanic type of chronic suppurative otitis media. Indian J Otol 2005;11:13-6.

[13] Loy AH, Tan AL, Lu PK. Microbiology of chronic suppurative otitis media in Singapore. Singapore Med J 2002;43(6):296-9.

[14] Lakshmipathi G, Bhaskaran CS. Bacteriology of chronic suppurative otitis media. J Indian Med Assoc 1965;45(8):436-40.

[15] Gulati J, Tandon PL, Singh W, et al. Study of bacterial flora in chronic suppurative otitis media. Indian J Otolaryngol Head Neck Surg 1969;21(4):198-202.

[16] Ayyagari A, Pancholi VK, Pandhi SC, et al. Anaerobic bacteria in chronic otitis media. Indian J Med Res 1981;73:860-5.

[17] Vijaya D, Geeta SH. Microbiological study of discharging otitis media. Indian J Otol 2003;9:17-9.

[18] Naheed P, Khan Z, Khan IM, et al. Bacteriological study of patients with discharging otitis media-a rural study. Indian J Otol 2003;9(4):29-32.

[19] Rajendra Kumar PV. A study on the incidence and aetiology of deafness in a south Indian population. Indian J Otolaryngol Head Neck Surg 1974;26(3):1537.

[20] Gulati SK. Investigative profile in patients of chronic suppurative otitis media. Indian J Otol 1997;3(2):5962.

[21] Anupam M, Girish S, Devika N, et al. Bacteriological study of chronic suppurative otitis media. Indian J Otol 1999;5:87-91.

[22] Kuchal V. Antibiotic sensitivity pattern in chronic suppurative otitis media (Tubotympanic type) in Kumaon region. Indian J Otol 2010;16:17-21.

[23] Singh N, Bhaskar R. Microbiological study of otitis media. Indian J Otolaryngol Head Neck Surg 1972;24(4):161.

[24] Rao MV, Jayakar PA. Bacteriological study of CSOM. J Indian Med Assoc 1980;75:30-4.

[25] Rao BN, Reddy MS. Chronic suppurative otitis media-a prospective study. Indian J Otolaryngol Head Neck Surg 1994;3(2):72-7.

[26] Friedmann I. The pathology of acute and chronic infections of the middle ear cleft. Ann Otol Rhinol Laryngol 1971;80(3):391-6. 